\title{
Communication Disorders \\ Following Traumatic Brain Injury
}

\author{
Edilene Curvelo Hora, Liane Viana Santana, \\ Lyvia de Jesus Santos, Gizelle de Oliveira Souza, \\ Analys Vasconcelos Pimentel, \\ Natalia Tenório Cavalcante Bezerra, \\ Sylvia Rodrigues de Freitas Doria, \\ Tiago Pinheiro Vaz de Carvalho, \\ Afonso Abreu Mendes Júnior, \\ Jessica Almeida Rodrigues, \\ Renata Julie Porto Leite Lopes and Ricardo Fakhouri
}

Additional information is available at the end of the chapter

http://dx.doi.org/10.5772/57321

\section{Introduction}

Traumatic brain injury (TBI) constitutes a public health problem of great significance with importance in both morbidity and mortality, accounting for approximately 15 to $20 \%$ of deaths in people between five and 35 years of age and responsible for $1 \%$ of all adult deaths.[1-2]

In the United States, about 59 million people every year die following TBI. This represents one third of all injury-related deaths. Furthermore, 90,000 individuals suffer from permanent incapacity related to TBI.[3]

In Brazil, data from the Ministry of Health (2011)[4] shows that 145,842 deaths occurred due to external causes, and amongst all injuries associated with these external causes, TBI stood out in terms of magnitude, as it was one of the most common injuries.[5]

Trauma caused by traffic accidents is one of the most frequent causes of death in individuals aged 10 to 24 . There is an imbalance in the prevalence of the risk of traffic-related trauma in developed countries and in developing ones, with the higher risk being found in the latter. 
Factors include the infrastructure of a country and the accelerated motorization of its population.[6]

The main causes of TBI include violent aggression, transportation accidents, and falls, the former two being the most prevalent. TBI victims are mostly young males.[7-10] TBI-related consequences extend beyond recorded fatalities and can also be observed in victims who survive trauma.

These individuals may present physical, cognitive, communication, and behavioural disabilities and incapacities at several levels, in addition to suffering problems on social and occupational levels.[11-12] The consequences of trauma consequences also touch the victims' families, who can be considered hidden victims. A crisis in the family system often arises, as well as the emergence of diseases that compromise the family's ability to function and recover.[13]

The participation of the speech therapist in the multidisciplinary team providing care to TBI victims is of great importance because this professional will be able to assess the specific needs of the victims at an early stage, regarding their communicative skills and other related problems (eating and swallowing difficulties), in order to prevent, minimize, or eliminate possible trauma sequelae.[14]

According to the American Speech-Language-Hearing Association (ASHA), patients with traumatic brain injury may experience difficulties in finding words to express themselves or in understanding an idea through speech, writing, and/or reading. Additionally, the muscles of the mouth, face, and the respiratory system can present changes in tone and coordination such that a speech motor disorder called dysarthria may result.[15] These language and/or speech and cognitive alterations compromise an individual's communication to varying degrees, ranging from minimal to extensive.

Speech and language production processes include distinct activities in the cerebral cortex. Therefore, different types of alterations in the Central Nervous System (CNS) may result in various kinds of language and/or speech disorders.[15]

For better understanding of communication disorders this chapter will address the importance of communication and language, as well as interdisciplinary approach victims of traumatic brain injury.

\section{Communication: An essential instrument in human relations}

Communication is a method by which the sharing of thoughts, feelings, ideas, and messages occurs, and it can influence the behaviour of those who respond according to their own beliefs, values, cultures, and life stories. Communication can be defined as "the capacity to exchange or discuss ideas, to dialogue, to converse with the aim of an understanding between the parties".[16] Communication, then, is an instrument of great importance in the realization and development of work, leisure, education, relationships, conversation, and negotiation.[17]

Communication, an instrument that is indispensable to interpersonal interaction is not only restricted to verbal language and the utilization of vocabulary. Rather, it also comprises other 
methods, such as gestures and body language, facial expressions, signs, figures, objects, colours, which is to say, it also includes visual signs, which are responsible for ensuring efficacy in the conversation process.[17] Visual signs are often the only components of certain conversations, a fact which highlights their great importance in the realization of communication.

The linguistic component is characterized by biological and social aspects and it characteristically favours adapting to the surrounding environment. These components include phonological, syntactic, semantic, and pragmatic aspects of language, described below. [18]

The capacity to surpass auditory perception and develop metaphonological abilities constitutes, in effect, a reflection upon the phonological aspects of a language, which is referred to as "phonological conscience", and which is an ability that is an important prerequisite in the development of written language.[19]

Syntax is the part of linguistics that is dedicated to the study of the rules and principles that govern the organization of a sentence's constituents. Semantics, on the other hand, examine the meaning of a word and of the relation between signs and its referents.

Pragmatic theories basically focus on two factors: communicative functions and conversational skills. Communicative functions are broad and abstract, and they reflect the communicative intention of the speaker; they involve motivation and the goals the speaker aims to achieve in communicating with the other individual. Conversational skills refers to a subject's capacity to participate in an interactive sequence of spoken acts, with the objective of communicative exchange.[19]

The ability to converse involves an interactive sequence of spoken acts and is the result of communicative exchange between two or more interlocutors inserted into a social context.[20] Besides this sequence, efficient conversation requires the interlocutors' compliance with the rule of taking turns, their commitment to the theme being discussed, and the capacity to adapt to participants and situations.[21]

Language is thus conceptualized as a "privileged instrument of inter-human communication and the privileged vehicle of thought".[22] Its organized use as a social rule and communicative mode of interaction are expressed and perceived in social culture. Social rules are organized by signs that express ideas that are manifested in speech, which makes communication with others possible[18]

The symbol comes from imitation, and representation is the use of the symbolic function of language. During the sensorimotor period, children's mental structures improve, and they form new constructions and start to associate and represent new signs. In this stage, the roots of thoughts are found in actions and in the mechanisms overriding linguistic fact, and so the role of language is an accessory in the construction of knowledge. In the transitory period between the sensorimotor and pre-operatory stages, the use of gestures with communicative interaction is accompanied by speech (babbling). Oral expression and the use of gestures develop in parallel with the development of communication. Communication is thereby characterized by the capacity to exchange information, express oneself, and interact with others, developing knowledge bases and expanding one's concepts in order to develop language.[23] 
In any sphere, communication is necessary, and such communication only occurs with the participation of two or more elements (transmitter and receiver) that transmit information using the means of language both verbal and nonverbal, resulting in an exchange of knowledge, which is to say that in order for the message to be transmitted and understood, it is necessary for the transmitter and receiver to promote mutual interaction.[24]

Among other forms of communication, nonverbal communication is a means of transmitting information. Vivacious gestures elicit responses, and one could almost argue that happens in accordance with an elaborate secret code that remains unwritten, acknowledged by none, but understood by all.[25]

Scholars have sought to demonstrate that children, through symbolic activity, develop instruments of language during their interactions with each other. As the children appropriate this language, they become capable of controlling their environment using gestures, facial expressions, and the emission of sounds, which function as a diffuse communication that constitutes the pre-verbal phase. After that, practical intelligence and speech are integrated, making verbal thought and language more rational.[26]

B. F. Skinner's book Verbal Behavior (1957), which deals with verbal behaviour and its function in children's acquisition of language, presents the idea of language reduced to a set of verbal responses associated with situations, in accordance with the Stimulus-Response model of conditioned reflexes. According to this theory, children learn language through imitation and reinforcement; in other words, the acquisition of language is considered a process of storing reinforcements.[27]

Interpersonal relations are revealed in thoughts, ideas, and feelings, and they transmit information that permeates the human condition. Scientific evidence suggests that the ability to develop language is innate and that the universal aspects of language acquisition are established in the structure of the human brain and are susceptible to sociocultural influences.[28]

Evidence collected from clinical observation shows how behaviour relates to mental processes and has long aroused interest. Different philosophical trends were instrumental in developing contemporary neurology. In the early 19th century, Franz Joseph Gall (1757-1828) spread the idea of phrenology that claimed an analysis of the skull's surface made it possible to determine whether or not a mental function had been developed. Followers of this philosophy attributed 35 different types of "organs" in the brain, each of which corresponded to a certain function. According to the theory, the "sense of language and of the word" was located in the frontal lobe of the brain.[22, 29-31] The scientific community eventually abandoned such ideas due to the lack of substantiated hypotheses.

In the mid-19th century, anthropologist Paul Broca's (1824-1880) important discoveries favoured the theory of cerebral localization, as suggested by Gall in his studies. Broca described patients who presented with impairment in the production of speech and in the preservation of language comprehension, and he identified lesions in the frontal lobes of the left cerebral hemisphere, an area which became known as "Broca's area" and which is responsible for "the functional center of language" and the syndrome became known as "Broca's aphasia".[22,29-30] 
The neurologist Carl Wernicke (1848-1904) awoke an interest in types of injuries that were different from those described by Broca, but that also presented impairments in language comprehension. These lesions corresponded to the temporal cortex of the left cerebral hemisphere (referred to as "Wernecke's area"), and the syndrome became known as "Wernecke's aphasia".[22,29-30] The two areas, Broca's and Wernicke's, are integrated by bundles of nerve fibres known as the arcuate fasciculus (Figure 1). In the majority of individuals, the cortical language areas are located in the left hemisphere of the brain.

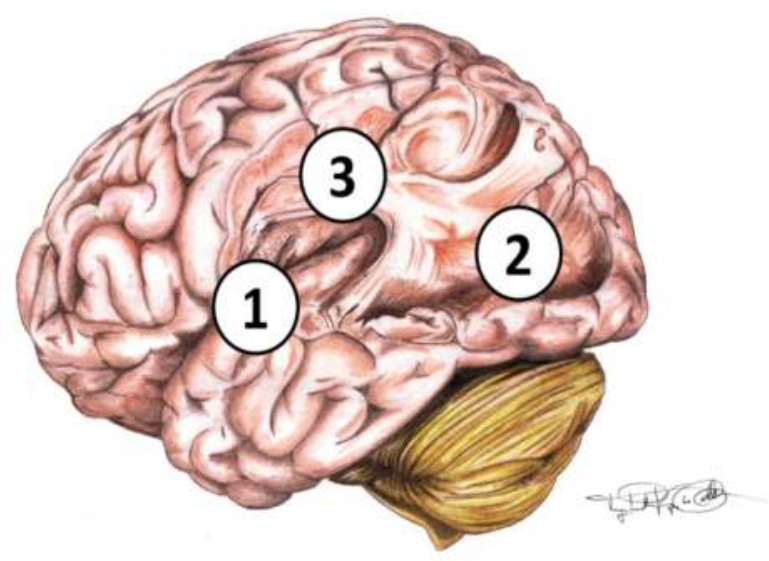

Figure 1. Language areas of the brain, 1: Broca's Area; 2: Wernicke's Area; 3: Arcuate Fasciculus. Illustration: Tiago Carvalho

The language process has been described through the neural mechanisms by which its main functions are performed. The sounds produced by speech require the incorporation of various pieces of information so as to generate the pattern of muscular activation necessary for verbal fluency.[31] The parts of the cerebral cortex used in the emission of speech deal with auditory information (temporal lobe), somatosensory information (parietal lobe), and motor information (frontal lobe). Together with the cerebellum, basal ganglia (primarily the thalamus), and the brain stem, interconnections between the brain's regions are responsible for the production of speech.[22,31-32]

One of the most studied functions in the field of neurolinguistics is a language and have the cognitive deficits associated with the mastery of this executive function. These deficits are responsible for the communication difficulties of patients who are injured in this cerebral area. Observations to this effect have motivated investigations into the importance of the relationship between cognitive mastery, executive functioning, and semantic knowledge. The use of computer programs in patient rehabilitation has been noteworthy, especially for patients with aphasia.[32] 
In the field of healthcare, communication is incredibly relevant. Trauma victims with TBI may have cerebral injuries or may acquire neurological damage, resulting in language disorders that make the patients' social lives more difficult. It is in this context that communication between patients and healthcare professionals, primarily nonverbal communication, is fundamental and needs to be and understood by health professionals.[33]

Keeping in mind that speech production processes involve different activities in distinct areas of the cortical regions of the brain, it is understandable that disturbances in speech and language mechanisms appear as a consequence to different types of changes in the central nervous system, as in the examples of TBI and cerebrovascular accidents resulting in aphasia, apraxia, and dysarthria.[33]

These disorders can compromise the quality of life for both the patients and their families and therefore should continue to be studied throughout the patient's life. This will enable healthcare professionals to provide improvements in treatment and better quality of life post-trauma.

The existence of man is only possible because of communication, and we are communicative beings par excellence. Communication permeates every aspect of our lives; from birth we exert influence on and are influenced by the environment in which we live. Over the course of our lives, the development of communication becomes more complex due to the necessity to master language, reading, the reasoning process, and an analysis of the world and of ourselves..[34]

\section{Language}

Language is an example of a higher brain function whose development is primarily based on a genetically-determined anatomic structure, but also on verbal stimulation from the outside environment. Language development depends not only on a perceptual motor reaction between perception and praxis, but also on a complex act involving cognition.[35-37]

A finite system of principles and rules that permits both the speaker to codify signs into sounds and the listener to decodify sounds into signs is based on the principles of language. This finite system, however, has the potential to be infinitely creative in the sense that it permits the speaker and the listener to create and understand an infinite set of new grammatical sentences.[35,38]

Neurolinguistics is the science of cerebral mechanisms underlying the comprehension, production, and abstract knowledge of language, be it spoken, signed, or written. The majority of studies on the physiology of language have focused on two chief entryways of linguistic information into the cognitive system: auditory input and visual input.[39]

Neurologically speaking, the term "language" seems to be grounded in thought itself, and sometimes it even seems to be synonymous with thought. The moment a new word is acquired has an impact on a child's development as this activity becomes a tool for analysis and synthesis and enables both an understanding of the child's surroundings and the self-regulation of the child's conduct.[40] 
An interdisciplinary nature is attributed to language because it is the object of study in various branches of science. Moreover, language is also an instrument used in social interactions between individuals seeking to communicate in different contexts, and it permeates the thoughts of those who use it, mediates relationships between humans, and is responsible for the transmission of sociocultural customs and values.[41-42]

The use of language depends on multiple types of knowledge and includes linguistic, conceptual, and perceptual non-linguistic systems of information. Knowledge is expressed through phonological, syntactic, semantic, and discursive structures. Because it is an elaborate and highly complex process, alterations in language can happen on any of the aforementioned levels and can compromise both oral and graphic communication.[40]

It is through the visual and auditory systems that language reaches the brain, while the motor system produces spoken and written discourse. When speaking, we produce and articulate sounds that have meaning and are vehicles of ideational expression.[35]

Even though the left hemisphere normally dominates language, the right hemisphere has abilities that are significant for language comprehension. Moreover, the corpus callosum allows synergistic interactions between the hemispheres in order to produce language. Besides the interaction between Broca's and Wernecke's areas, this processing results in many capabilities, such as designation, articulation, comprehension, and the use of grammar.[43]

The left hemisphere analyses sequentially, and so, in the majority of people, it acts as the anatomical and physiological substrate of the language function. The right hemisphere, on the other hand, analyses spatially.[44]

Language is organized around a fundamental dual capacity: a lexical capacity (establishing; retaining in memory; receptively and productively using a significant amount of meaningsignifier-referent associations) and a grammatical capacity having to do with the organization on a sequencing level and structural dependencies between words (enunciated phrases) and sequences (paragraphs and discourse).[1]

This dual capacity is joined by an instrumental social dimension referred to as "the pragmatics of language".[45] Linguistic information can be transmitted in the form of discourse and written text, but it is the content of the message that is essential to the higher levels of language comprehension processes, such as the achievement of inferences and associations between pieces of textual information.[44]

With cranial traumas, what should be emphasized is oral language comprehension, which is defined as being related to that which is remembered from completed communication or from the application of information garnered from what has been heard, or which is connected to casual relationships established between elements in communication so as to give them coherence.[46]

Understanding involves a series of steps that, starting from a statement, allows one to rediscover the original idea. It is the process of [re]constructing meanings from spoken discourse, and through this process, the listener generally acquires information or knowledge through language. However, there is also oral communication with the ultimate goal of 
establishing and/or maintaining social relationships, of initiating interaction for the purpose of entertainment, seduction, pleasure, or even to confuse or deceive, forging a given understanding.[44]

An important concept in the representation of words is the mental lexicon, i.e., a mental stock of word-related data that includes information about semantics, syntax, pronunciation, and sound patterns. The process of accessing lexical representations (words) in the mental lexicon is influenced by the "auditory neighborhood" of words, which is defined as the number of words that differ from the target word by one phoneme.[47]

Words with more neighbours are identified more slowly, and there can be competition when activating different words during the recognition of discourse. Additionally, it is believed that the mental lexicon is organized into a network of specific information in which the organization of representations involves relationships between words so that words representing similar meanings are connected and tend to be grouped closer together.[48]

In order to understand words, individuals pass through pre-lexical processing stages: decodifying signals that enter acoustically and are translated into a phonological code. Subsequently, the lexical representation that best fits the auditory signal can be chosen from the mental lexicon (lexical selection). The form of the word selected initially activates the theme (storage of grammatical information) and, following that, the meaning of the word.[49]

Comprehension includes the following: the recognition or judicious guesswork of vocabulary; remembering orality-related systems, facts, and details (purposes embedded in the propositions of the speaker); and the identification and interconnections of ideas and the principles therein. In completing these tasks, listeners make use of their ability to draw inferences about content or perceived proposition.[50]

To do this, listeners must grasp, interpret, and evaluate oral information within the communicative context using their knowledge of the world and of vocabulary. Logical relationships, the chain of communicative functions, the use of gestures, and rhetorical resources all significantly influence the comprehension of oral language.[48]

In 1978, DeRenzi and Faglioni,[51] developed the Token Test, a tool widely used to quantify difficulties in listening comprehension in order to assess the receptive function of language. It makes use of short statements, and applying the test is both quick and easy.

This test is composed of 36 verbal instructions that demonstrate an increasing level of linguistic complexity, which are divided into six parts. To administer the test, twenty pieces are needed. These pieces are two different shapes (square and circle), two sizes (small and large), and four colours (black, yellow, green, and white). They are arranged according to the instructions provided by the test's authors. The participants respond to instructions such as: "Touch the circle"; "Touch the yellow square"; and "Touch the large black circle and small green square". The scores can range from 0 to 36 points and are obtained by totalling the scores of each test item. A score of 29 to 36 indicates comprehension impairment; a score of 25 to 28, mild impairment; a score of 17 to 24 , moderate impairment; a score of 9 to 16 , severe impairment; and a score of 0 to 8 , very severe impairment. 
Few studies[15,52-53] have investigated linguistic alterations in TBI victims, which means that sequelae are underestimated and underdiagnosed. The consequences of these alterations are not only physical but also psychosocial, potentially compromising patients' social relationships. Furthermore, as we have argued, oral comprehension skills are undoubtedly essential to everyday life, as they determine our ability to understand oral messages, a key feature of communication's effectiveness.

There has been confirmation, achieved through the most modern neuroimaging techniques, that the left hemisphere is responsible for the language process in virtually all right-handed individuals, as well as in more than half of left-handed and ambidextrous individuals.[54]

A TBI patient's communication can change according to language disorders. Some individuals may have difficulty understanding or producing oral and written language, or they may have difficulty with the more subtle aspects of communication, like body language or emotional and nonverbal cues.

Our study assessed 122 TBI patients between 14 and 83 years old who were admitted into a public trauma referral hospital located in a city in north-eastern Brazil in 2012. It revealed that most TBI victims presented some level of oral comprehension impairment after traumatic brain injury, ranging from mild to moderate alterations.[55]

\section{Post-TBI communication disorders}

Aphasia, dysarthria, and apraxias are among the chief alterations in communication that are caused by TBI-related disorders or neurological damage.[33]

There are also cognitive-linguistic disorders. These cognitive-communicative impairments were defined and classified by ASHA in 1988 as any change in communication resulting in cognitive deficits (such as memory, attention, and logical reasoning) that produce symptoms and difficulties in communication that are traditionally considered unclassifiable and that present within normal language during formal tests, such as the Boston Test. However, this type of data and the impact of these changes after the cerebral injury remain imprecise.[56-57]

Aphasia is a multimodal disorder that affects reading, writing, auditory comprehension, and orally-expressed language. It should not, however, be regarded as a specific disorder, as other cognitive processes, such as attention and short-term auditory memory, can also be involved.[58]

Thus, aphasia is essentially a linguistic processing disorder in which the mechanisms that transform thought into language are blocked. Furthermore, the disorder compromises initiative, creativity, and the ability to perform calculations, i.e., skills that call on the use of internal speech.[59]

Aphasia's cause is neurological in origin and could be associated with several aetiologies (vascular, infection, tumour, cranial trauma, degenerative disease, demyelinating diseases, and toxic disorders).[59-61] Its classification is described in Table 1 below. 


\begin{tabular}{lll}
\hline Emissive Aphasias & $\frac{\text { Broca's Aphasia }}{\text { Conduction Aphasia }}$ \\
\cline { 2 - 3 } APHASIAS & Receptive Aphasias & $\frac{\text { Wernicke's Aphasia }}{\text { Transcortical Sensory Aphasia }}$ \\
& Mixed Aphasias & Mixed Transcortical Aphasia \\
\hline & Global Aphasia \\
\hline
\end{tabular}

Table 1. Classification of Aphasias

More common expressive or motor aphasia is associated with injuries involving the frontal language centre in the dominant hemisphere (Broca's area) and is therefore mainly associated with an inability to translate spoken concepts into meaningful sounds, or in other words, to produce speech. The result is speech that is not fluent, with pauses between words or phrases.

Conduction aphasia is characterized by phonemic paraphasias, anomies and semantic paraphasias during the conversation. The speech may appear with hesitation and selfcorrections. A striking feature of this type of aphasia corresponds to errors found in the repetition test.

Another type of non-fluent aphasia is transcortical motor aphasia, whose main feature is the reduction of speech. Spontaneous language is extremely reduced, and its expression is slow and short.

Receptive or sensorial aphasia is related to injuries to the posterior language area in the dominant hemisphere. Wernicke's aphasia is the most serious comprehension aphasia associated with problems in the comprehension and formulation of speech.

In transcortical sensory aphasia, oral expression is fluent; at the same time, severe and moderate comprehension deficits appear; and there are semantic paraphasias, anomies and circumlocutions.

Anomic or amnesic aphasia is primarily characterized by semantic changes, paraphrases and anomies.

The mixed forms of aphasia are conditions that exhibit characteristics of the several manifestations described. As an example, there are: transcortical motor aphasia, in which oral expression is characterized by stereotypes and echolalia; and global aphasia, in which the patient has a severe impairment of oral expression and listening comprehension.

As the expressive aspects of speech depend upon the normal functioning receptive aspects, language expression may also be impaired in individuals with sensory aphasia, who may present with unintelligible words, changing words (paraphasia), and other expressive disorders related to speech production. Thus, the main differences between motor and sensory 
aphasia are in language comprehension, which is only slightly affected in the former but severely affected in the latter; and in speech, with non-fluent aphasia in motor aphasia and fluent aphasia in the sensory variety.[62]

It is important to emphasize and describe the changes in oral language abilities when dealing with aphasic syndrome.[63]

Verbal fluency: this criterion is mainly used to differentiate between fluent and non-fluent aphasic syndromes. With aphasia in which oral language is fluent, an ease of articulation can be seen even in long sentences; generally, this type of aphasia is the result of a posterior lesion. Non-fluent aphasia is characterized by a difficulty in initiating oral production, which causes strain. This type of aphasia is associated with anterior lesions.[64-66] Muteness would be the most extreme degree of reduction in fluency, whereas, logorrhoea is a marked increase in the number of words produced in a certain amount of time.[66]

Anomia: a difficulty or inability to recall names of objects, leading to a restriction in vocabulary. It is present at different levels in every type of aphasia and has several causes. Attempts to compensate for this difficulty often feature synonyms or circumlocution. While anomia does not exclusively affect substantive words, nouns are the most compromised class of words. [60,61-64] For example, sufferers have difficulty in recalling or retrieving the words in speech. The processes for retrieving the words are the same for aphasic and not aphasic, but for people with the disease, the operation becomes slow, cumbersome and often ineffective.

Paraphrase: occurs when a subject, while trying to say a word, substitutes the word with a phrase,[67] for example, what serves as combing for comb.

Circumlocution: expression which takes place when a patient can neither grasp the main theme of the enunciation nor discuss it. In his statement he touches upon the theme but does not manage to specifically discuss it,[67] for example, a wooden object which has a backrest, four legs and is used to sit on is a chair.

Repetition: one of the most basic mechanisms of human language; however in patients with aphasia, it can be impacted in different ways. The phonemic pathway is used to repeat notwords, while words are repeated by accessing the meaning. Repetition is kept intact in extrasylvian (transcortical) aphasia but harmed in perisylvian aphasia (Broca, Wernicke, conduction, and global).[64] An example of this condition is: "the house, the house, the house".

Auditory comprehension: a complex function resulting from the processing of speech sounds in Wernecke's area; occurs when concepts related to a registered word are activated and selected. The process involves several areas with different modalities and hierarchies that are distributed throughout the entire brain. Generally, it is more affected in fluent aphasia. $[59,66,68]$

Agrammatism: the disorganization of syntactic rules present in language, which leads to a significant reduction in an individual's statements. It is characterized by an almost telegraphic style, where prepositions, articles, conjunctions, and pronouns are omitted, but nouns, adjectives, and verbs (almost always in the infinitive) are preserved. A loss of prosody and a lack of declension for gender, time, and number can also be observed. It is a hallmark of Broca's 
aphasia.[60,63-64] An example of agrammatism is: "Father to lead to the college", note the absence of "my" "will go" "me" "to" and "a".

Stereotyping: perseverative and involuntary repetitions of a certain type of behaviour. Patients will use restricted verbal production, with or without linguistic meaning, every time that they attempt oral or written communication. It is present in Broca's aphasia.[60,63-64,66] For example, a patient produces this sound: eeeeeeeeeee, eeeeeee, eeeee...

Perseveration: maintaining the same response for distinct stimuli. Patients will use a word incorrectly right after it has been used in a different, more appropriate context. This is also associated with Broca's aphasia.[60,63-64]

Jargon: discourse that has no message, in which syntax and semantics are absent; it is language that is incomprehensible, without meaning, and spoken at a rapid pace. It is present in the more serious fluent aphasias.[60,63-64] For example, "It's going to rain upon noodle stones plantation."

Echolalia: the repetition of an interlocutor's sounds, in an unsolicited context, with no communicative purpose.[64,66] An example of echolalia is: chair, chair, chair...

Paraphasia: the substitution of letters, syllables, or words during discourse.

Phonological paraphasia: a wrong choice during the act of articulation, characterized by distortion in the production of phonemes. Patients substitute one phoneme for another, [60,64,66-67] for example, plants for pants.

Phonemic paraphasia: a change in the phonological level of language; it consists of substitutions influenced by production context or by similarity of certain traits. It can be manifested as a change, an omission, or an addition of phonemes or syllables and is present in a large number of fluent aphasias.[60,63,66-67] An example is shark for sharp.

Morphemic paraphasia: a change characterized by the substitution of words' grammatical morphemes,[67] for example: talk for talking.

Formal paraphasia: occurs when a swap, substitution, addition, or omission results in a different word in the language, without being characterized as a semantic swap, for example, goat for coat.

Verbal paraphasia: when the patient makes a substitution in an oral statement and cannot identify its relation to the content or form of the statement, for example, tiger for lion.

Semantic paraphasia: occurs when one word is substituted with another that has the same semantic context,[60] for example, pen for pencil.

Neologism: phonemic or graphemic sequences that obey a language's rules and resemble words, but do not exist in that language. When trying to say a word, patients will substitute the word with a sequence of meaningless sounds.[64] An example of this is, "The cake was eatful" instead of eatable.

Reduction: Decrease in the number of enunciations in a certain amount of time,[67] for example: "the girl's hair is beautiful" for "girl... beautiful hair". 
Suppression: the complete absence of oral or graphic emission. This term can be considered a synonym for muteness when used in the context of oral statements.[67]

The sensorimotor sequelae of TBI can impair an individual's communication and affect the ability to produce intelligible speech. This happens when the trauma affects the areas of the brain that are responsible for the execution of movements necessary to produce speech and triggers a neuromotor disorder called dysarthria.[69] Dysarthria is characterized by slowness, weakness, and/or lack of muscle coordination related to the speech function. Its main consequence is a reduction in speech's intelligibility, which limits the speaker's communicative ability and social participation.[15,70]

It often develops after damage to the central or peripheral nervous system, which mainly affects laryngeal function, causing weakness or lack or muscle coordination during speech, as well as changes in the oral statement.[71]

For production to render intelligible speech, the phonoarticulatory apparatus needs to be working in perfect symphony; along with the oral cavity, the pulmonary, laryngeal, and pharyngeal structures form the apparatus, and any change to any of these will consequently impact speech intelligibility.[71-72] The dysarthria occurs when there is an impairment in the motor apparatuses necessary for oral production (which are: breathing, phonation, resonance, articulation, and prosody) following a central or peripheral neurological change. This fact justifies the emergence of the terms "dysarthrophonia" and "neurological dysphonia" as synonyms for dysarthria in order to describe this condition, which is not just a change in articulation.[73]

There are several types of dysarthria that vary according to the degree and location of the injury: flaccid dysarthria, spastic dysarthria, unilateral upper motor neuron dysarthria, hypokinetic dysarthria, hyperkinetic dysarthria, ataxic dysarthria, and lastly, mixed dysarthria[74]. The most common symptoms range from a decreased rate of speech, vagueness, articulation, slow, irregular speech to a lack of change in pitch or intensity.[75-76]

With TBI, flaccid dysarthria is the most common type. In flaccid dysarthria, the injury is located in the lower motor neuron, which is peripheral, but it can also emerge due to some cranial nerve lesions. Nerve conduction is impaired at a point between the cell body and the muscle, and the resulting changes are flaccidity, weakness, atrophy, and fasciculations.[73] Thus, motor function is changed, potentially resulting in muscle paralysis, a breathier and more monotone voice, hypernasality, imprecise articulation of consonants, diminished volume and predominantly pharyngolaryngeal resonance.[71] Loss of muscle mass is also common for this type of dysarthria.

Spastic dysarthria can also emerge after closed TBI and is caused by a bilateral lesion to the upper motor neuron, which causes an increase in muscle tone, spasticity, and weakness. Among its main characteristics are: a rough, stressed voice; tight, choked sounds; monotone; imprecise articulation of consonants; and hypernasality.[73]

Another type of dysarthria that can occur due to trauma injury is mixed dysarthria, in which changes typical of several types of dysarthria all emerge at the same time and have no sort of 
pattern. This is because the injuries involve multiple areas of the central and peripheral nervous system. This type can also occur in cases of stroke, degenerative, metabolic, and toxic diseases, and infectious diseases of the central or peripheral nervous system.

Research[77] conducted at the São Paulo Hospital (HSP), Brazil, developed a profile of dysarthric patients which showed that traumatic cranial lesions were the second most frequent aetiology related to dysarthria, with male patients prevailing due to both the higher rate of males in automobile accidents and the higher frequency of flaccid dysarthria in TBI patients. In another Brazilian study,[33] the prevalence of traumatic cranial injury in individuals attended to at the Acquired Neurological Disorders Outpatient Service of the Speech Pathology Department at UNIFESP was $75.6 \%$. The majority of these cases also involved male patients, and $33 \%$ of patients were diagnosed with dysarthria.

After a diagnosis of dysarthria has been made and its aetiology determined, it is up to a speech therapist to evaluate the patient and connect phonological signs to neurological changes, so as to better determine short-, mid-, and long-term therapy practices that align with both the patient's prognosis and a general clinical view of the case. In severe cases of TBI, the occurrence of dysphagia associated with dysarthria is common. Therefore, it is necessary to have a clear and precise diagnosis so that adequate rehabilitation can be carried out.[73]

Apraxia should also be brought to attention and seen as an articulation disorder that leads to the loss of the ability to perform previously learned motor acts. In apraxia, there is a difficulty in associating the voluntary programming of the position of the muscles that form speech organs with the sequential movement of these muscle groups, which prevents the formation of appropriate language. Apraxic patients present these symptoms, although they exhibit no abnormalities in the motor and sensory systems, or in comprehension, cooperation, and attention skills. It is damage to the primary motor cortex that causes apraxia.[78]

They are, therefore, speech articulation disorders that result in a loss of the ability to programme and organize the position of the speech apparatus to voluntarily produce phonemes, or of the sequence of muscle movements to produce words; a loss which is not, however, accompanied by the weakness, slowness, or lack of coordination that affects these same muscles in reflexive or involuntary movements caused by cerebral lesion.[1]

\section{Interdisciplinary approach}

Interdisciplinary care for TBI victims performed by a multidisciplinary team is recommended during post-trauma treatment. It is necessary to evaluate the specific needs of the individual, aiming not only for preservation of live, but also for quality of life.

Family participation is vitally important in each treatment phase. A team with a speech therapist, doctor, nurse, occupational therapist, psychologist, physical therapist, social worker, and nutritionist, among other types of professionals, is highly suggested.

A speech therapist has the goal of helping patients improve their communicative abilities, in addition to addressing other concerns such as chewing and swallowing. It is important to start 
rehabilitation as soon as possible, as this encourages and optimizes the initial spontaneous recovery process.[14]

The main goal of a speech therapist, then, is to maximize a patient's communication.[79-80] In the initial phases, the objective of communication rehabilitation is to offer sufficient support in order to facilitate the recovery of the communicative function. Subsequently, the focus of the intervention becomes the generalization of communication skills in activities with varying contexts.[79]

The rehabilitation process involves combining suitable intervention approaches for each case, such as: behavioural approaches; skills and specific process training; guidelines; metacognitive approaches (tasks that require analysis of semantic similarities, main ideas and topics, and narrative schemes, among others); interventions focused on people living with the individual (training in the use of communication strategies and assistive technology, for example); and use of augmentative and alternative communication (AAC) that can be defined as "any resource that can be used to encode and transmit a message without requiring writing skills or vocalization"..[1,73,79,81]

Regarding the use of supplementary systems and alternative communication in the therapeutic process with patients with brain injury, although studies are scarce, the literature indicates these systems as facilitators of communication, i.e., as resources for the rehabilitation of speech and communication facilitation in day-to-day situations. There have also been descriptions of adaptations and the use of high-tech systems, mostly for cases of cerebral palsy.[1, 4-5 ]

In order for a TBI patient's communication to be optimized or to be made possible, cognitive stimulation should be started as soon as possible. The goal of an intervention is to maximize patients' potential and promote faster, more organized evolution through the stimulation of various sensory modalities, using familiar materials and resources.[82] With evolution on a cognitive level, the individual usually begins to communicate better and can start to speak, read, or write again. Such resources should be used in the process of care, as well as in the process of rehabilitating the linguistic and cognitive aspects that changed as a result of TBI.[73]

It is essential that patients in a state of mental confusion are oriented about the circumstantial, spatial, and temporal aspects that can help to contextualize their situation, such as: what happened, where they are, their location in time, what will be done at that moment, and other relevant pieces of information.[83]

When patients can control their attention, even for a limited amount of time, certain strategies can be employed that make message comprehension easier for the patients. These can include: always facing the patient while speaking, using repetition and redundancy, favouring short and direct sentences, speaking more slowly, minimizing the presence of noise or other stimuli, and using warning signals that gear the patient's attention towards receiving information.[83] These strategies can also be used by other members of the team and by the patient's relatives.[73,83]

In dysarthria cases where communication is impacted, rehabilitation should also take into account an intervention concerning specific aspects of speech production, with the aim of optimizing the patient's intelligibility.[79,84] 
Most neurological damage resulting from TBI does not occur at the time of the injury, but rather over the course of the hours and days after the accident, thus it can be prevented or treated.[85]

Early indicators of a bad prognosis should be identified in the clinical history and, most importantly, during a physical examination of the patient. The doctor should have some knowledge of the patient so that he can try to return to use the window of time between the trauma and the ensuing damage in which to prevent future consequences, and in doing so prevent secondary damage.[86]

The nurse also provides care to these victims and should be able to obtain data on the patient's history, perform a physical examination, and provide prompt treatment in order to preserve life and prevent secondary damage.[87] The systematization of nursing care is not only necessary, but almost of utmost importance.

There is little scientific evidence concerning physical therapy intervention and the improvement of communication disorders in individuals with traumatic brain injury, but this area of healthcare has a range of behaviours that complement the treatment of the voice, speech, and language functions within an interdisciplinary context. To achieve adequate vocal performance, it is necessary to teach breathing.

Patients with head trauma commonly suffer losses in respiratory efficiency and effectiveness; when using accessory muscles, more energy is expended per respiratory cycle. The ideal is that the gas exchange process take the least possible toll on their energy reserves, and for this, focus is put on the diaphragm, extensive musculature adapted to breathing. Respiratory therapy is highly recommended for lung restructuring, maintaining the force and strength of respiratory musculature, increasing gas exchange efficiency, and eliminating the use of accessory muscles.[88-89] Techniques vary from manual manoeuvres to release the diaphragm and diaphragmatic breathing to the use of devices known to motivate inspiratory flow and volume.[90]

Another problem for cranial injury victims besides respiratory disorders is aphasia. One method that has evolved over the past decade is Constraint-Induced Language Therapy. This therapy consists of restricting the aphasic patient's communication to verbal communication and prohibiting any other method of communication, either gestural or written. The therapy session is long and tiring, held for an average of two or three hours a day over a period of about two weeks. It has been well-received in the clinical setting, and results have been promising.[91] Another advantage is that regardless of whether the aphonic presents with an acute or chronic condition, therapy brings about clinical improvement, and studies have shown changes of $28 \%$ to $47 \%$ in patients with chronic aphasia.[92]

Communication goes far beyond spoken language. Interaction using gestures and signs is crucial for those who have lost voice function and/or hearing after a traumatic brain injury. An injury to the precentral gyrus of the frontal lobe of the cerebrum, for example, can affect the primary movements, compromising the execution of gestures and signs. Physical therapy works to develop gross and fine motor skills, vision skills, sensory processing skills, movement coordination, and appropriateness of tone - key points for communication.[93] In situations 
where various muscle groups are affected by spasticity, physical therapists may recommend systemic drug therapy to contribute to the reduction of tone, in addition to recommending physical measurements, exercise and orthotics.[94]

From a psychological perspective, there are several areas that can directly affect communication. For over four decades, psychology has developed, through studies on language acquisition, into different models of theoretical and methodological concepts that serve as linguistic techniques and behaviour. The field of psycholinguistics aims to address conduct or behaviour related to language in the context of a subject's psychological and social functioning.

Neuropsychology is an area of psychology that allows greater dialogue between different professionals in the neurosciences for the purpose of establishing knowledge about cognitive functions, behaviour, and the functioning of the Central Nervous System (CNS).

This area holds extensive knowledge about clinical and research practices working mainly with the assessment (neuropsychological tests) and treatment (neuropsychological rehabilitation) of disorders that can occur in the Central Nervous System, such as trauma.[95]

In Neuropsychology, each function of the Central Nervous System is detailed, and this enables more effectively-directed rehabilitation. With TBI, in which most accidents occur in the region of the Frontal Lobe (considered executive functions), there are several studies of the components involved in this area, such as working memory, planning, problem solving, decision making, fluency, and inhibition control, among others.[96]

The main evaluations performed that concern linguistic components are: fluency, repetition, comprehension, and naming. These components can lead to more exact diagnoses about the seriousness of the spoken, written, and comprehended language impairment of a patient who has Central Nervous System dysfunction,[97] and can also help the patient's rehabilitation and communication.

Patients with Central Nervous System Dysfunction require more intensive care from their families because, besides having difficulties with motor and cognitive functions, they experience changes in personality and behaviour. It is important that patients and families work in an interdisciplinary way, using humanized reception and the structure provided by help groups in order to supplement the patients' rehabilitation and the social stability of the family.

\section{Conclusion}

Communication disorders can occur regardless of the severity of an injury, and they have a major impact on the level of discourse and the social exchanges. They can have a negative effect on the patients' recovery process, reintegration into the community, independence, familial interactions, and professional and academic success.

In this context, we stress the importance of the interdisciplinary approach in the follow-up treatment of these victims, so that prognosis and rehabilitation, as well as post-TBI quality of life, may improve. 


\section{Author details}

Edilene Curvelo Hora*, Liane Viana Santana, Lyvia de Jesus Santos, Gizelle de Oliveira Souza, Analys Vasconcelos Pimentel, Natalia Tenório Cavalcante Bezerra, Sylvia Rodrigues de Freitas Doria, Tiago Pinheiro Vaz de Carvalho, Afonso Abreu Mendes Júnior, Jessica Almeida Rodrigues, Renata Julie Porto Leite Lopes and Ricardo Fakhouri

*Address all correspondence to: edilene@ufs.br

Health Sciences Post-Graduate Programme, Academic Trauma League (LITRAUMA), Federal University of Sergipe, Brazil

\section{References}

[1] World Health Organization. Neurotrauma. 2013. http://www.who.int/ violence_injury_prevention/road_traffic/activities/neurotrauma/en (accessed 05 July 2013).

[2] Gentile JKA, Himuro HS, Rojas SSO, Veiga VC, Amaya LEC, Carvalho JC. Condutas no paciente com trauma cranioencefálico. Revista da Sociedade Brasileira de Clínica Médica 2011;9(1). http://files.bvs.br/upload/S/1679-1010/2011/v9n1/a1730.pdf (accessed 05 July 2013).

[3] Aghakhani N, Azami M, Jasemi M, Khoshsima M, Eghtedar S, Rahbar N. Epidemiology of Traumatic Brain Injury in Urmia, Iran. Iranian Red Crescent Medical Journal 2013;15(2). http://www.ncbi.nlm.nih.gov/pmc/articles/PMC3652507/ (accessed 05 July 2013).

[4] Brasil, Ministério da Saúde. Estatística e mortalidade. Óbitos por ocorrência segundo causas externas de morbidade e mortalidade do Brasil, 2011. http://tabnet.datasus.gov.br/cgi/tabcgi.exe?sim/cnv/ext10uf.def (accessed 05 July 2013).

[5] Pinheiro AL, De Almeida FM, Barbosa IV, Mesquita ME, Borges SRM, De Figueiredo CZM. Principais causas associadas ao traumatismo cranioencefálico em idosos. Enfermería global 2011;10(22). http://scielo.isciii.es/pdf/eg/v10n22/pt_clinica4.pdf (accessed 05 July 2013).

[6] Cheng-Min H, Jeffrey CL, Miranda JJ, Hyder AA. Traumatismos causados por El tránsito en países em desarrollo: agenda de investigación y de acción. Revista Peruana de Medicina Experimental y Salud Pública 2010;27(2) 243-247.

[7] Mackenzie EJ. Epidemiology of injuries: current trends and future challenges. Epidemiol Rev 2000;22 112-119. 
[8] Koizumi MS, Lebrão ML, Mello-Jorge MHP, Primerano V. Morbidity and Mortality from traumatic brain lesion in São Paulo, 1997. Arquivos de Neuropsiquiatria 2000;58 $1-13$.

[9] Kay A, Teasdale G. Head Lesion in the United Kingdom. World J Sur 2001;25 1210-1220.

[10] JE Boswell, McErlean M, Verdile VP. Prevalence of traumatic brain lesion in an ED population. Am J Emerg Med 2002;20 177-180.

[11] The Levati, Farina ML, Vecchi G, Rossanda M, Marrubini N. Prognosis of severe head injuries. J Neurosurg 1982;57 779-783.

[12] Junque C, Bruna O, Marató M. Head trauma: an approach to neuropsychology and speech therapy - practical guide for professionals and families. $1^{\text {st }}$ ed. São Paulo (SP): Santos Publisher; 2001.

[13] Hora EC, Sousa RMC, Ribeiro COM, Nunes MS, Araújo RCV, Santos ACFS et al. Traumatic Brain Injury: consequences and family needs. In: Agrawal A (ed) Brain Injury: functional aspects, rehabilitation and prevention. Rijeka: InTech; 2012 161-174. http://www.intechopen.com/books/brain-injury-functional-aspects-rehabilitationand-prevention (accessed 28 September 2013).

[14] Junqué C, Bruna O, Mataró M. Traumatismos Cranioencefálicos: uma abordagem da neuropsicologia e da fonoaudiologia. São Paulo: Editora Santos; 2001.

[15] American Speech Hearing Association. http://www.asha.org/public/speech/disorders/TBI/ (accessed 20 August 2012).

[16] Ferreira ABH. Dicionário Aurélio Básico da Língua Portuguesa. Rio de Janeiro: Nova Fronteira; 1999.

[17] Souza TNU, Payão LMC. Apraxia da fala adquirida e desenvolvimental: semelhanças e diferenças. Revista da Sociedade Brasileira de Fonoaudiologia 2008;13(2) São Paulo April/June.

[18] Mansur LL. Linguagem. In: Malloy-Diniz, Fuentes D, Mattos P, Abreu N e cols. Avaliação neuropsicológica. Porto Alegre: Artmed; 2010.

[19] Almeida EC, Duarte PM. Consciência fonológica. Rio de Janeiro: Revinter; 2003.

[20] Mayor A. La pragmática del lenguaje: consideraciones para la intervención. Leng. Comun Madri 1991;(7) 17- 21.

[21] Hage SRV, Resegue MM, Viveiros DCS, Pacheco EF. Análise do perfil das habilidades pragmáticas em crianças pequenas normais. Pró-Fono Revista de Atualização Científica 2007, Barueri (SP); 19(1) 49-58.

[22] Gil R. As afasias. São Paulo: Editora Santos; 2002. 
[23] Piaget J-P. O nascimento da inteligência na criança. $4^{\mathrm{a}}$ ed. Rio de Janeiro: LTC Editora; 1987. Edição original de 1936.

[24] Aguiar VT. O verbal e o não verbal. São Paulo, Editora UNESP; 2004.

[25] Corraze J. As comunicações não verbais. Rio de Janeiro, Editora Zahar; 1982.

[26] Vygotsky LS. Pensamento e linguagem. São Paulo: Martins Fontes; 2000.

[27] Ardila R. Verbal Behavior de B.F. Skinner: sua importância no estudo do comportamento. Revista Brasileira de Terapia Comportamental Cognitivista 2007;9(2) 195-197.

[28] Pinker S. Tábula rasa: a negação contemporânea da natureza humana. São Paulo: Companhia das Letras; 2004.

[29] Alvarez AMMA, Sanchez ML, Carvalho IAM. Neuroaudiologia e linguagem. In: Fuentes, D, Malloy-Diniz LF, Camargo CHP, Consenza, RM e cols. Neuropsicologia teoria e prática. Porto Alegre: Artmed; 2008.

[30] Consenza RM, Fuentes D, Malloy-Diniz LF. A evolução das ideias sobre a relação entre cérebro, comportamento e cognição. In: Fuentes D, Malloy-Diniz LF, Camargo CHP, Consenza RM e cols. Neuropsicologia teoria e prática. Porto Alegre: Artmed; 2008.

[31] Girodo CM, Silveira VNS, Girodo GAM. Afasias. In: Fuentes D, Malloy-Diniz LF, Camargo $\mathrm{CHP}$, Consenza RM e cols. Neuropsicologia teoria e prática. Porto Alegre: Artmed; 2008.

[32] Nicholas M, Sinotte MP, Helm-Estabrooks N. C-Speak Aphasia Alternative Communication Program for People with Severe Aphasia: Importance of Executive Functioning and Semantic Knowledge. Neuropsychological Rehabilitation 2011; 21(3) 322366.

[33] Talarico TR, Venegas MJ, Ortiz KZ. Perfil populacional de pacientes com distúrbios da comunicação humana decorrentes de lesão cerebral, assistidos em hospital terciário. Revista CEFAC 2011;13(2) 330-339.

[34] Silva MJP. Comunicação tem remédio: a comunicação nas relações interpessoais em saúde. São Paulo: Editora Gente; 1996.

[35] Castaño J. Bases neurobiológicas del lenguaje y sus alteraciones. Revista de Neurologia 2003 ; 36(8) 781-785

[36] Johansson B, Berglund P, Ronnback L. Mental fatigue and impaired information processing after mild and moderate traumatic brain injury. Brain Inj 9009; 23(13) 1027-1040.

[37] Norrie J, Heitger M, Leathem J, Anderson T, Jones R, Flett R. Mild traumatic brain injury and fatigue: a prospective longitudinal study. Brain Injury 2010; 24(13) 1528-1538. 
[38] Podell K, Gifford K, Bougakov D, Goldberg E. Neuropsychological assessment in traumatic brain injury. Psychiatric Clinics of North America 2010; 33(4) 855-876.

[39] Jean-Francois D, Thierry G, Cardebat D. Renewal of the Neurophysiology of Language Functional Neuroimaging Physiol 2005; Rev 85 49 -95.

[40] Luria AR, Yudovich FI. Linguagem e desenvolvimento intelectual na criança (Trad.: José Cláudio de A. Abreu). Porto Alegre: Artes Médicas, 1985.

[41] Eysenck M, Keane M. Limitações da atenção e do desempenho. Manual de psicologia cognitiva. $5^{\text {th }}$ ed. Tradução de: Magda França Lopes. Porto Alegre: Artmed; 2007

[42] Flanagan DP. The achievement test desk reference (ATDR). Boston: Allyn and Bacon; 2008.

[43] Bear MF, Connors BW, Paradiso MA. Neurociências: desvendando o sistema nervoso. $3^{\underline{a}}$ edição. Porto Alegre: Artmed; 2008.

[44] Puyuelo M, Rondal J. Manual de desenvolvimento e alterações da linguagem na criança e no adulto. Porto Alegre, Artes Médicas; 2007.

[45] Fonseca RP, Ferreira GD, Liedtke FV, Muller JL, Sarmento TF, Parente MAMP. Alterações cognitivas, comunicativas e emocionais após lesão hemisférica direita: em busca de uma caracterização da síndrome do hemisfério direito. Psicologia USP 2006;17(4): 241-262.

[46] Joly MCRA, Dias AS. Evidências de validade de uma prova informatizada de linguagem oral - Bilo. Psicologia: Teoria e Prática 2009;11(2) 50-68.

[47] Rassovsky Y, Satz P, Alfano MS, Light RK. Functional outcome in TBI I: neuropsychological, emotional, and behavioral mediators. Journal of Clinical and Experimental Neuropsicologia 2006; 28 (4) 567-580.

[48] Gazzaniga MS, Ivry RB, Mangun GR. Neurociência cognitiva. Porto Alegre, RS: Artmed; 2006.

[49] Munjal SK, Panda NK, Pathak A. Audiological deficits after closed head injury. J Trauma 2010;68(1) 13-18.

[50] Cavalcanti A, Galvão C. Terapia Ocupacional: fundamentação e prática. Rio de Janeiro: Guanabara Koogan; 2007.

[51] DeRenzi E, Vignolo LA. The Token Test: A sensitive test to detect receptive disturbances in aphasics. Brain 1962;85 556-678.

[52] Lesser R. Verbal and non-verbal memory components in the Token Test. Neuropsychologia 1976;14(1) 79-85.

[53] Nelson T, Galvão OF. Discrepancies between the Token Test Procedure Original and Reduced Brazilian Adaptation. Neurobiology 2010;73(1) 155-159. 
[54] Marin L, Queiroz MS. The actuality of traffic accidents in the age of speed: an overview. Cad Public Health 2000;16(1) 7-21.

[55] Santana LV, Hora EC. Impairment in oral language comprehension among victims of Traumatic Brain Injury. Dissertação de Mestrado, NPGME UFS; 2013.

[56] Ortiz KZ, Araújo AA. Traumatismo craniencefálico: Avaliação e reabilitação fonoaudiológica. In: Ortiz KZ (org). Distúrbios neurológicos adquiridos: linguagem e cognição. São Paulo: Manole; 2010. p284-300.

[57] Marini A, Galetto V, Zampieri E, Vorano L, Zettin M, Carlomagno S. Narrative Language in traumatic brain injury. Neuropsychologia 2011;49 2904-2910.

[58] Berthier ML. Poststroke aphasia: epidemiology, pathophysiology and treatment. Drugs Aging 2005;22 163-182.

[59] Amasio AR. Aphasia. N Engl Med 1992;326: 531-9.

[60] Cupello RCM, Miranda ABR. Rupturas em trajetos cerebrais subjacentes a alguns sinais neurolingüísticos encontrados em diversos tipos de afasia. Fono atual 2003;23 42-59.

[61] Mac-Kay APMG. Afasia. In: Mac-Kay APMG, Assencio-Ferreira VJ, Ferri-Ferreira TMS. Afasias e demências: avaliação e tratamento fonoaudiológico 2003. São Paulo: Santos;47-59.

[62] Murdoch BE. Desenvolvimento da fala e distúrbios da linguagem: uma abordagem neuroanatômica e neurofisiológica. Rio de Janeiro: Revinter; 1997. p113-123.

[63] Jakubovicz R, Cupello R. Introdução à afasia: elementos para o diagnóstico e terapia. $6^{\text {th }}$ ed. Rio de Janeiro: Revinter; 1996, 276p.

[64] Engelhart E, Laks J, Rozenthal M. Neuropsicologia. VII - Distúrbios da linguagem. Afasia - aspectos neuroclínicos/neuropsicológicos. Revista Brasileira de Neurologia 1996;32 21-26.

[65] Goodglass H, Kaplan E. The assessment of aphasia and related disorders. Philadelphia: Lea\&Febiger; 1972 .

[66] Mansur LL, Senaha MLH. Distúrbios de linguagem oral e escrita e hemisfério esquerdo. In: Nitrini R, Caramelli P, Mansur LL. Neuropsicologia: das bases anatômicas à reabilitação. São Paulo: Clínica Neurológica do Hospital das Clínicas da Faculdade de Medicina da Universidade de São Paulo; 1996. p183-201.

[67] Ortiz KZ. Distúrbios neurológicos adquiridos: linguagem e cognição. Rio de Janeiro: Revinter; 2005.

[68] Benson DF. Aphasia. In: Heilman KM, Valenstein E. Clinical neuropsychology. $3^{\text {rd }}$ ed. New York: Oxford; 1993. p17-36. 
[69] Dykstra AD, Hakel ME, Adams SG. Application of the ICF in reduced speech intelligibility in dysarthria. Semin Speech Lang 2008;28(4) 301-311.

[70] Guo YE, Togher L. The impact of dysarthria on everyday communication after traumatic brain injury: a pilot study. Brain Inj 2008; 22(1) 83-97.

[71] Carrilo L, Karin ZO. Vocal analusis (auditory - perceptual and acoustic) in dysarthrias. Pró-Fono Revista de Atualização Científica 2007;19(4) 381-386.

[72] Barreto SS, Ortiz KZ. Medidas de inteligibilidade nos distúrbios da fala: revisão crítica da literatura: [revisão]. Pró-Fono 2008;20(3) 201-206.

[73] Ortiz KZ. Distúrbios neurológicos adquiridos: fala e deglutição. Barueri: Manole: 2010.

[74] Ortiz KZ. Distúrbios neurológicos adquiridos: fala e deglutição. Barueri: Manole; 2006.

[75] Tjaden K, Wilding GE. Rate and loudness manipulations in dysarthria: acoustic and perceptual findings. J Speech Lang Hear Res 2004;47(4) 766-783.

[76] Kent RD, Duffy JR, Slama A, Kent JF, Clift A. Clinicoanatomic studies in dysarthria: review, critique, and directions for research. J Speech Lang Hear Res 2001;44(3) 535-551.

[77] Ribeiro AF, Ortiz KZ. Populational profile of dysarthric patients assisted in a tertiary hospital. Rev Soc Bras Fonoaudiol 2009;14(3) 446-453.

[78] Souza TNU, Payão LMC. Apraxia da fala adquirida e desenvolvimental: semelhanças e diferenças. Rev Soc Bras Fonoaudiol 2008;13(2) 193-202

[79] Cicerone KD, Dahlberg C, Kalmar K, Langenbahn DM, Malec JF, Bergquist TF, et al. Evidence-based cognitive rehabilitation: recommendations for clinical practice. Arch Phys Med Rehabil 2000;81(12) 1596-1615.

[80] MacDonald S, Wiseman-Hakes C. Knowledge translation in ABI rehabilitation: a modelo for consolidating and applying the evidence for cognitive-communication interventions. Brain Inj 2010;24(3) 486-508.

[81] Wallace T, Bradshaw A. Technologies and strategies for people with communication problems following brain injury or stroke. NeuroRehabil 2011; 28(3) 199-209.

[82] Chabok SY, Kapourchali SR, Leili EK, Saberi A, Mohtasham-Amiri Z. Effective factors on linguistic disorder acute phase following traumatic brain injury in adults. Neuropsychologia 2012;50 1444-1450.

[83] Shelton C, Shryock M. Effectiveness of communication/interaction strategies with patients who have neurological injuries in a rehabilitation setting. Brain Inj 2007; 21(12) 1259-1266. 
[84] Sellars C, Hughes T, Langhorne P. Speech and language for dysarthria due to nonprogressive brain damage. Cochrane Database Syst Ren 2005;20(3) 2088.

[85] Brain Trauma Foundation. Guidelines for the management of severe traumatic brain injury, $3^{\text {rd }}$ Edition. Journal of Neurotrauma 2007; 24.

[86] Brain Trauma Foundation. Early indicators of prognosis in severe traumatic brain injury. 2000.

[87] Pereira $\mathrm{N}$ et al. $\mathrm{O}$ cuidado do enfermeiro à vítima de traumatismo cranioencefálico: uma revisão da literatura. Revista Interdisciplinar NOVAFAPI 2011;4(3) 60-65.

[88] Gething AD, Williams M, Davies B. Inspiratory resistive loading improves cycling capacity: a placebo controlled trial. British Journal of Sports Medicine 2004;38 730736.

[89] Silva AMO, Boin IFS, Pareja JC, Magna LA. Analysis of respiratory function in obese patients submitted to fobi-capella surgery. Revista do Colégio Brasileiro de Cirurgiões 2007;34 314-320.

[90] Irwin S, Teckilin J. Fisioterapia Cardiopulmonar. São Paulo: Manole; 2003

[91] Pulvermuller F, Neininger B, Elbert T, et al. Constraint-induced therapy of chronic aphasia after stroke. Stroke 2001;32(7) 1621-1626.

[92] Moss A, Nicholas M. Language rehabilitation in chronic aphasia and time postonset: a review of single-subject data. Stroke 2006;37(12) 3043-3051.

[93] Gunel MK. Rehabilitation of children with cerebral palsy from a physiotherapist's perspective. Acta Orthop Traumatol Turc 2009;43(2) 173-180.

[94] Gracies JM, Elovic E, McGuire JR, Nance P., Simpson DM. Tradicional phamacologic treatments for spasticity part II: systemic treatments. In: Mayer NH, Simpsnon DM (ed.). Spasticity: we move self - study activity; 2002. p65-93.

[95] Consenza RM, Fuentes D, Malloy-Diniz LF. A evolução das ideias sobre a relação entre cérebro, comportamento e cognição. In: Fuentes D, Malloy-Diniz LF, Camargo CHP, Consenza RM e cols. Neuropsicologia teoria e prática. Porto Alegre: Artmed; 2008.

[96] Malloy-Diniz L, Sedo M, Fuentes D, Leite WB. Neuropsicologia das funções executivas. In: Fuentes D, Malloy-Diniz LF, Camargo CHP, Consenza RM e cols. Neuropsicologia teoria e prática. Porto Alegre: Artmed; 2008.

[97] Girodo CM, Silveira VNS, Girodo GAM. Afasias. Fuentes D, Malloy-Diniz LF, Camargo CHP, Consenza RM e cols. Neuropsicologia teoria e prática. Porto Alegre: Artmed; 2008. 